\title{
Which growth standards should be used to identify large- and small-for-gestational age infants of mothers with type 1 diabetes? A pre-specified analysis of the CONCEPTT trial
}

Claire L. Meek ${ }^{1,2^{*}}$ (D) Rosa Corcoy ${ }^{3,4,5}$, Elizabeth Asztalos ${ }^{6}$, Laura C. Kusinski ${ }^{1,2}$, Esther López ${ }^{4,7}$, Denice S. Feig ${ }^{8,9}$, Helen R. Murphy ${ }^{2,10,11}$ and On behalf of the CONCEPTT collaborative group

\begin{abstract}
Background: Offspring of women with type 1 diabetes are at increased risk of fetal growth patterns which are associated with perinatal morbidity. Our aim was to compare rates of large- and small-for-gestational age (LGA; SGA) defined according to different criteria, using data from the Continuous Glucose Monitoring in Type 1 Diabetes Pregnancy Trial (CONCEPTT).

Methods: This was a pre-specified analysis of CONCEPTT involving 225 pregnant women and liveborn infants from 31 international centres (ClinicalTrials.gov NCT01788527; registered 11/2/2013). Infants were weighed immediately at birth and GROW, INTERGROWTH and WHO centiles were calculated. Relative risk ratios, sensitivity and specificity were used to assess the different growth standards with respect to perinatal outcomes, including neonatal hypoglycaemia, hyperbilirubinaemia, respiratory distress, neonatal intensive care unit (NICU) admission and a composite neonatal outcome.

Results: Accelerated fetal growth was common, with mean birthweight percentiles of 82.1, 85.7 and 63.9 and LGA rates of 62,67 and 30\% using GROW, INTERGROWTH and WHO standards respectively. Corresponding rates of SGA were 2.2, 1.3 and 8.9\% respectively. LGA defined according to GROW centiles showed stronger associations with preterm delivery, neonatal hypoglycaemia, hyperbilirubinaemia and NICU admission. Infants born $>97.7$ th centile were at highest risk of complications. SGA defined according to INTERGROWTH centiles showed slightly stronger associations with perinatal outcomes.

Conclusions: GROW and INTERGROWTH standards performed similarly and identified similar numbers of neonates with LGA and SGA. GROW-defined LGA and INTERGROWTH-defined SGA had slightly stronger associations with neonatal complications. WHO standards underestimated size in preterm infants and are less applicable for use in type 1 diabetes.

\footnotetext{
* Correspondence: clm70@cam.ac.uk

1 Institute of Metabolic Science, University of Cambridge, Addenbrooke's

Hospital, Box 289, Cambridge CB2 0QQ, UK

${ }^{2}$ Cambridge Universities NHS Foundation Trust, Cambridge, UK

Full list of author information is available at the end of the article
}

C The Author(s). 2021 Open Access This article is licensed under a Creative Commons Attribution 4.0 International License, which permits use, sharing, adaptation, distribution and reproduction in any medium or format, as long as you give appropriate credit to the original author(s) and the source, provide a link to the Creative Commons licence, and indicate if changes were made. The images or other third party material in this article are included in the article's Creative Commons licence, unless indicated otherwise in a credit line to the material. If material is not included in the article's Creative Commons licence and your intended use is not permitted by statutory regulation or exceeds the permitted use, you will need to obtain permission directly from the copyright holder. To view a copy of this licence, visit http://creativecommons.org/licenses/by/4.0/. The Creative Commons Public Domain Dedication waiver (http://creativecommons.org/publicdomain/zero/1.0/) applies to the data made available in this article, unless otherwise stated in a credit line to the data. 
(Continued from previous page)

Trial registration: This trial is registered with ClinicalTrials.gov. number NCT01788527. Trial registered 11/2/2013.

Keywords: Large-for-gestational-age, Small for gestational age, Macrosomia, Birth-weight, Diabetes, Pregnancy, CONCEPTT, Growth standards, INTERGROWTH, GROW

\section{Background}

Birth weight is an important indicator of neonatal wellbeing $[1,2]$. Infants who are small- or large-forgestational-age (SGA or LGA; birth weight $<10$ th or $>90$ th percentile) experience higher risks of morbidity and mortality $[3,4]$. Recent population based data suggests that despite improvements in care, infants of women with type 1 diabetes (T1D) remain at high risk of LGA (rates 50\%) [5]. LGA rates were also high in the CONCEPTT international randomized controlled trial of the use of continuous glucose monitoring (CGM) in comparison with capillary blood glucose monitoring in pregnant women with T1D [6]. LGA rates were significantly reduced in infants of women who used CGM (53\% vs $69 \%$ in home blood glucose monitoring group), likely due to improved glycaemic control [7].

Currently there is controversy internationally about which growth standards to use to compare LGA rates in different populations. Customised (Gestation Related Optimum Weight; GROW) centiles [8] were used in CONCEPTT for the comparison of birthweight across international sites and diagnosis of LGA. GROW centiles are customised to maternal and neonatal factors including maternal ethnicity, height, weight, parity, neonatal sex and gestational age [7, 9]. GROW provides countryspecific customised centiles, enabling international comparisons between populations. Advocates suggest that customised centiles reduce over-investigation of normal fetuses and can more accurately predict fetuses at increased risk of stillbirth and perinatal mortality $[9,10]$.

Other growth standards based on data from the INTE RGROWTH-21st study (20,486 infants across eight geographical areas) and the World Health Organisation (WHO) Multicentre Growth Reference Study (8500 infants across six geographical areas) $[11,12]$ are used internationally. Both standards assume $<3.5 \%$ of the variability in growth is due to differences in ethnicity and population when circumstances are optimal (e.g healthy, well-nourished mothers) [13]. INTE RGROWTH-21st standards focus on fetal growth and neonatal size at birth, while the WHO charts assess weight-for-age at 0-60 months [12]. In addition, some studies in diabetes pregnancy report standard deviation (SD) based birthweight categorisation.

Population studies comparing growth standards have focused on the identification of SGA in general maternity populations $[9,10,14]$. However, in infants of women with T1D, LGA is five times more common than in the background maternity population [5]. Identification of these infants may improve outcomes by increasing surveillance and targeting interventions to those at highest risk [15]. Furthermore, identification of a single growth standard with optimal performance in T1D pregnancies would allow future standardisation of research outcomes.

A further challenge in growth assessment in T1D pregnancy regards the use of growth standards in preterm infants. GROW and INTERGROWTH approach preterm growth differently. GROW centiles are based upon the Hadlock formula for gestational age, suggesting that the growth of preterm and term infants should be exactly the same at any timepoint [16]. The INTE RGROWTH standards do not make this assumption and are based on the size of preterm infants at birth. Although this approach seems more scientifically justifiable, as growth abnormalities may contribute to preterm birth, the INTERGROWTH standards were based upon limited data from preterm (before 37 weeks) and very preterm babies (before 34 weeks), which introduces uncertainty [17]. More studies in preterm infants are needed to identify which growth standard performs best in this group [18].

Our aim was therefore to assess the incidence of LGA and SGA using different definitions and growth standards in T1D pregnancy, and to assess which standard was able to identify infants at highest risk of perinatal complications.

\section{Methods}

The recruitment, rationale and methodology of the CONCEPTT trial are described in detail elsewhere [6] (ClinicalTrials.gov NCT01788527; registered 11/2/2013; see Appendix S1 for CONCEPTT collaborative group). In brief, women with T1D were recruited before or during pregnancy and randomized to real-time continuous glucose monitoring or capillary glucose monitoring alone. Women in the capillary glucose monitoring group also had short periods of masked continuous glucose monitoring, to allow comparison of glycaemic control between groups. Women were followed-up until delivery with collection of information about birth outcomes. Local policies in the study sites were used to determine the optimal timing and method of delivery. 
Pre-specified neonatal outcomes for the CONCEPTT study included miscarriage, stillbirth, neonatal death, birth injury, shoulder dystocia, preterm delivery, neonatal hypoglycaemia requiring intravenous dextrose, hyperbilirubinaemia, respiratory distress syndrome, neonatal intensive care unit admission requiring a duration of at least $24 \mathrm{~h}$, total length of hospital stay, birthweight, macrosomia (birthweight $\geq 4 \mathrm{~kg}$ ), LGA ( $>90$ th centile) and SGA $(<10$ th centile) based on customised centiles. Definitions for CONCEPTT outcomes are given in Appendix S2 and were standardised across all the CONCEPTT sites. This data was collected using participant's medical records. For the CONCEPTT trial, the composite neonatal endpoint incorporated pregnancy loss (miscarriage, stillbirth, or neonatal death), birth injury, neonatal hypoglycaemia, hyperbilirubinaemia, respiratory distress syndrome, or neonatal intensive care admission $>24 \mathrm{~h}$. This pre-specified secondary analysis includes data from pregnant and pre-pregnant recruits who became pregnant during the 6-month pre-pregnancy trial and who gave birth to a liveborn infant. Therefore, in the current study, the composite neonatal endpoint incorporated birth injury, neonatal hypoglycaemia, hyperbilirubinaemia, respiratory distress syndrome, or neonatal intensive care admission $>24 \mathrm{~h}$ but not pregnancy loss.

\section{Calculation of birth weight centiles}

Gestational age at delivery was based upon ultrasound measurements in early pregnancy (approximately 12 weeks). Maternal height and weight required for the GROW calculation was measured by trained staff at the baseline study visit. As the CONCEPTT study recruited women in early pregnancy, this was considered broadly similar to pre-pregnancy weight.

GROW centiles were calculated using version 8 (2017) of the GROW calculator using data about maternal selfreported ethnicity, parity, height, weight, gestational age at birth and neonatal sex [8]. INTERGROWTH centiles were calculated using the windows app (available at https://intergrowth21.tghn.org/intergrowth-21stapplications/; accessed 31/03/2019) using information about infant sex, weight and age (0-60 months). WHO centiles were calculated using data about infant sex, weight and age (0 months) using the igrowup package for Stata (available at http://www.who.int/childgrowth/ software/en/; accessed 31/03/2019). To demonstrate differences and similarities between centile-based methods and SD-based methods in the assessment of birth weight, we also included SD-based definitions for LGA (+ 1 and 2 SDs) using methods which were commonly used in the literature. Calculation of SGA using definitions $<5$ th and $<2.5$ th percentile resulted in too few infants to permit meaningful analysis.

\section{Statistical analysis}

Continuous data were described as mean (SD) and categorical data as $\mathrm{n}$ (\%) as appropriate. Data regarding birthweight were analysed as percentiles. An unadjusted log-binomial regression model was used to assess associations between different growth standards, at different thresholds, and perinatal outcomes. Results are presented as relative risk ratios (RR) and 95\% confidence intervals. As other comparable studies in the literature provide odds ratios, we have included a table in the supplementary material with odds ratios and 95\% confidence intervals, calculated using unadjusted logistic regression (Table S1). The threshold for statistical significance was $p<0.05$. We considered that the best performing growth standard to be that which was significantly associated with the most suboptimal perinatal outcomes.

\section{Results}

Two hundred twenty-five women and infants were included in this analysis, including 200 from the pregnancy arm and 25 from the pre-pregnancy arm who became pregnant during the trial. Baseline characteristics and pregnancy outcomes are detailed in Table 1. Most women were over 30 years old (mean age 31.4 years), overweight (mean BMI $25.8 \mathrm{~kg} / \mathrm{m}^{2}$ ), of European or Mediterranean ethnicity $(86.2 \%)$ and approximately half used insulin pump therapy (48.9\%). They had T1D of 16.5 years' duration with suboptimal glucose levels $\left(\mathrm{HbA}_{1 \mathrm{c}} 6.9 \% ; 51.8 \mathrm{mmol} / \mathrm{mol}\right)$ in early pregnancy as defined by the trial eligibility criteria, which required $\mathrm{HbA}_{1 \mathrm{c}}>=6.5 \%(48 \mathrm{mmol} / \mathrm{mol})$. Their infants were born at 37.0 weeks of gestation, predominantly by Caesarean section (68.9\%).

Large-for-gestational-age (LGA) rates varied (Table 2. GROW: 62.2\%; INTERGROWTH 66.7\%; WHO 29.8\%) and there were also differences in the mean and median birthweight centile (Table 1. Mean centiles GROW: 82.1; INTERGROWTH 85.7; WHO 63.9 centiles; Median centiles GROW: 95.2; INTERGROWTH 95.0; WHO 73.6 centiles). Other measures of birth weight are shown in Table 2. Other common perinatal complications included neonatal hypoglycaemia (25.3\%), hyperbilirubinaemia (27.6\%), respiratory distress (8.4\%) which all contributed to frequent NICU admissions $>24 \mathrm{~h}$ (36.9\%). Birth injury and shoulder dystocia were uncommon, (1/ $225(0.4 \%))$ and only occurred in one infant who was considered LGA by all criteria. LGA according to GROW, INTERGROWTH and WHO criteria was associated with increased risks of perinatal complications (Table 2). While each growth standard was associated with some complications, no growth standard identified all complications studied. Increased birthweight according to GROW displayed more significant associations 
Table 1 Maternal Infant Characteristics. BMI: body mass index; GROW: gestation related optimum weight; NICU: neonatal intensive care unit; WHO: World Health Organisation. Composite outcome: birth injury, neonatal hypoglycaemia, hyperbilirubinaemia, respiratory distress syndrome, or neonatal intensive care admission. Diabetes complications defined as any retinopathy, neuropathy or nephropathy

\begin{tabular}{|c|c|}
\hline & $\begin{array}{l}\text { Mean (SD) or } n(\%) \\
n=225\end{array}$ \\
\hline \multicolumn{2}{|l|}{ MATERNAL CHARACTERISTICS } \\
\hline Maternal age, years & $31.4(4.5)$ \\
\hline BMl at enrolment, $\mathrm{kg} / \mathrm{m}^{2}$ & $25.8(4.6)$ \\
\hline Ethnicity European/ Mediterranean origin & $194(86.2)$ \\
\hline Primiparous & 89 (39.6) \\
\hline Duration of diabetes, years & $16.5(7.7)$ \\
\hline Diabetes complications & $58(25.8)$ \\
\hline Hypertension pre-pregnancy & $15(6.7)$ \\
\hline $\mathrm{HbA} 1 \mathrm{c}$ at randomisation $\mathrm{mmol} / \mathrm{mol}$ & $51.8(6.6)$ \\
\hline $\mathrm{HbA} 1 \mathrm{c}$ at randomisation \% & $6.9(0.6)$ \\
\hline Smoking & $20(8.9)$ \\
\hline Insulin pump & $110(48.9)$ \\
\hline \multicolumn{2}{|l|}{ INFANT CHARACTERISTICS } \\
\hline Sex (\% male) & $115(51.1)$ \\
\hline Gestational age at delivery & $37.0(1.6)$ \\
\hline \multicolumn{2}{|l|}{ BIRTHWEIGHT MEASURES } \\
\hline Birthweight g & $3583.6(705)$ \\
\hline Macrosomia $>=4 \mathrm{~kg}$ & 59 (26.2) Median (range) \\
\hline GROW centile & $82.1(25.9) 95.2(0.1-100.0)$ \\
\hline INTERGROWTH centile & $85.7(20.8) 95.0(3.9-100.0)$ \\
\hline WHO centile & $63.9(32.0) 73.6(0.0-100.0)$ \\
\hline \multicolumn{2}{|l|}{ OBSTETRIC AND PERINATAL OUTCOMES } \\
\hline Caesarean section & $155(68.9)$ \\
\hline Preterm delivery & 89 (39.6) \\
\hline Neonatal hypoglycaemia requiring intravenous dextrose & $57(25.3)$ \\
\hline NICU admission & $83(36.9)$ \\
\hline Hyperbilirubinaemia & $62(27.6)$ \\
\hline Respiratory distress & $19(8.4)$ \\
\hline Composite neonatal outcome & $107(47.6)$ \\
\hline
\end{tabular}

with perinatal outcomes than INTERGROWTH (i.e. with neonatal hypoglycemia, hyperbilirubinemia, NICU admission and the composite outcome).

Most perinatal complications demonstrated a U-shaped relationship with the birth centile (Fig. 1). Neonatal hypoglycaemia was most frequent in infants born extremely large for gestational age (ELGA; > 97.7th centile). In smaller infants $(<25$ th centile), GROW and INTE RGROWTH were associated with hyperbilirubinaemia, while WHO centiles at < 10th and/or <25th centile thresholds were associated with multiple outcomes, including NICU admission, hyperbilirubinaemia, respiratory distress and the composite outcome (Table 2; Fig. 1).
Overall GROW and INTERGROWTH standards performed similarly and identified similar numbers with LGA (slightly higher for INTERGROWTH) and SGA (slightly higher for GROW). These standards performed consistently regardless of sex, ethnicity and timing of delivery (see supporting Tables S2, S3, S4). The positive and negative predictive values of the neonatal outcomes and their associated sensitivity and specificity varied depending on outcome (Table 3). The WHO standards do not take gestational age at birth into account and therefore underestimated size in preterm infants. This resulted in a linear association between WHO centile and preterm delivery (Fig. 1). 
Table 2 Association of adverse neonatal outcomes with low and high birthweights after GROW, INTERGROWTH and WHO criteria. Relative risk ratios and 95\% confidence intervals are reported in comparison to all other pregnancies. Neonatal hypoglycaemia included only infants who required IV dextrose. GROW: gestation related optimum weight; NICU: neonatal intensive care unit; WHO: world health organisation. Composite outcome: birth injury, neonatal hypoglycaemia, hyperbilirubinaemia, respiratory distress syndrome, or neonatal intensive care admission. ${ }^{*} p \leq 0.05 ;{ }^{* *} p \leq 0.01 ;{ }^{* *} p \leq 0.001$

\begin{tabular}{|c|c|c|c|c|c|c|}
\hline & N (\%) & $\begin{array}{l}\text { Neonatal } \\
\text { hypoglycaemia } \\
\text { RR }(95 \% \mathrm{Cl})\end{array}$ & $\begin{array}{l}\text { NICU Admission } \\
\text { RR }(95 \% \mathrm{Cl})\end{array}$ & $\begin{array}{l}\text { Hyper- } \\
\text { bilirubinaemia } \\
\text { RR }(95 \% \mathrm{Cl})\end{array}$ & $\begin{array}{l}\text { Respiratory } \\
\text { Distress } \\
\text { RR }(95 \% \mathrm{Cl})\end{array}$ & $\begin{array}{l}\text { Composite } \\
\text { Outcome } \\
\text { RR }(95 \% \mathrm{Cl})\end{array}$ \\
\hline \multicolumn{7}{|c|}{ Birthweight $>84.1$ st centile (mean $+1 \mathrm{sd})$} \\
\hline GROW > 84.1st centile & $\begin{array}{l}146 / 225 \\
(64.9 \%)\end{array}$ & 1.66 (0.97 to 2.84$)$ & $\begin{array}{l}1.41(0.95 \text { to } \\
2.10)\end{array}$ & $1.56(0.94$ to 2.56$)$ & 2.03 (0.70 to 5.91$)$ & $1.46(1.05 \text { to } 2.02)^{*}$ \\
\hline $\begin{array}{l}\text { INTERGROWTH }>84.1 \mathrm{st} \\
\text { centile }\end{array}$ & $\begin{array}{l}167 / 225 \\
(74.2 \%)\end{array}$ & 1.45 (0.81 to 2.61$)$ & $\begin{array}{l}1.17 \text { (0.77 to } \\
1.77)\end{array}$ & 1.19 (0.71 to 1.99$)$ & $1.30(0.45$ to 3.77$)$ & $1.20(0.85$ to 1.69$)$ \\
\hline WHO $>84.1$ st centile & $\begin{array}{l}82 / 225 \\
(36.4 \%)\end{array}$ & 1.36 (0.87 to 2.13$)$ & $\begin{array}{l}0.99 \text { (0.69 to } \\
1.41)\end{array}$ & 0.77 (0.48 to 1.23$)$ & $0.80(0.32$ to 2.04$)$ & $1.00(0.75$ to 1.33$)$ \\
\hline \multicolumn{7}{|c|}{ Birthweight $>90$ th centile $($ mean $+1.28 \mathrm{sd})$} \\
\hline GROW $>90$ th centile & $\begin{array}{l}140 / 225 \\
(62.2 \%)\end{array}$ & $1.86(1.09 \text { to } 3.20)^{*}$ & $\begin{array}{l}1.49(1.01 \text { to } \\
2.21)^{*}\end{array}$ & 1.61 (0.99 to 2.62$)$ & 2.28 (0.78 to 6.63$)$ & $\begin{array}{l}1.56(1.13 \text { to } \\
2.16)^{* *}\end{array}$ \\
\hline $\begin{array}{l}\text { INTERGROWTH >90th } \\
\text { centile }\end{array}$ & $\begin{array}{l}150 / 225 \\
(66.7 \%)\end{array}$ & 1.69 (0.97 to 2.94$)$ & $\begin{array}{l}1.48 \text { (0.98 to } \\
2.22)\end{array}$ & 1.44 (0.87 to 2.36$)$ & $1.88(0.64$ to 5.45$)$ & $1.41(1.01 \text { to } 1.96)^{*}$ \\
\hline WHO >90th centile & $\begin{array}{l}67 / 225 \\
(29.8 \%)\end{array}$ & $1.48(0.94$ to 2.33$)$ & $\begin{array}{l}1.02 \text { (0.70 to } \\
1.47)\end{array}$ & $0.82(0.50$ to 1.34$)$ & $0.63(0.22$ to 1.82$)$ & $1.05(0.78$ to 1.41$)$ \\
\hline \multicolumn{7}{|c|}{ Birthweight $>97.7$ th centile (mean $+2 \mathrm{sd})$} \\
\hline GROW > 97.7th centile & $\begin{array}{l}95 / 225 \\
(42.2 \%)\end{array}$ & $2.35(1.47 \text { to } 3.75)^{* * *}$ & $\begin{array}{l}1.62(1.15 \text { to } \\
2.28)^{* *}\end{array}$ & $1.56(1.02 \text { to } 2.38)^{*}$ & $1.88(0.79$ to 4.50$)$ & $\begin{array}{l}1.50(1.14 \text { to } \\
1.97)^{* *}\end{array}$ \\
\hline $\begin{array}{l}\text { INTERGROWTH > 97.7th } \\
\text { centile }\end{array}$ & $\begin{array}{l}92 / 225 \\
(40.9 \%)\end{array}$ & $2.30(1.45 \text { to } 3.65)^{* * * *}$ & $\begin{array}{l}1.48(1.06 \text { to } \\
2.08)^{*}\end{array}$ & 1.19 (0.78 to 1.82$)$ & 1.61 (0.68 to 3.80$)$ & $1.42(1.08 \text { to } 1.86)^{*}$ \\
\hline WHO > 97.7th centile & $\begin{array}{l}28 / 225 \\
(12.4 \%)\end{array}$ & $2.29(1.45 \text { to } 3.61)^{* * *}$ & $\begin{array}{l}1.55(1.05 \text { to } \\
2.30)^{*}\end{array}$ & 0.90 (0.45 to 1.77$)$ & $1.32(0.41$ to 4.24$)$ & $1.33(0.95$ to 1.86$)$ \\
\hline \multicolumn{7}{|c|}{ Birthweight $<10$ th centile (<1.28 sd below mean) } \\
\hline GROW <10th centile & $5 / 225(2.2 \%)$ & 0.79 (0.13 to 4.60$)$ & $\begin{array}{l}1.65 \text { (0.79 to } \\
3.45)\end{array}$ & $2.24(1.06 \text { to } 4.73)^{*}$ & $\begin{array}{l}2.44(0.40 \text { to } \\
14.91)\end{array}$ & 1.27 (0.61 to 2.63$)$ \\
\hline $\begin{array}{l}\text { INTERGROWTH }<10 \text { th } \\
\text { centile }\end{array}$ & $3 / 225(1.3 \%)$ & Insufficient events & $\begin{array}{l}1.83 \text { (0.81 to } \\
4.14)\end{array}$ & $2.47(1.08 \text { to } 5.65)^{*}$ & $\begin{array}{l}4.11(0.78 \text { to } \\
21.63)\end{array}$ & 1.41 (0.63 to 3.18$)$ \\
\hline WHO $<10$ th centile & 20/225 (8.9\%) & 1.21 (0.59 to 2.45$)$ & $\begin{array}{l}1.90(1.31 \text { to } \\
2.77)^{* * *}\end{array}$ & $1.74(1.02 \text { to } 2.98)^{*}$ & $\begin{array}{l}3.66(1.47 \text { to } \\
9.11)^{* *}\end{array}$ & $\begin{array}{l}1.67(1.24 \text { to } \\
2.24)^{* * *}\end{array}$ \\
\hline \multicolumn{7}{|c|}{ Birthweight $<25$ th centile $(<0.675$ sd below mean) } \\
\hline GROW <25th centile & $13 / 225(5.8 \%)$ & 0.59 (0.16 to 2.17$)$ & $\begin{array}{l}1.05 \text { (0.51 to } \\
2.13)\end{array}$ & 1.43 (0.69 to 2.95$)$ & $1.92(0.50$ to 7.43$)$ & $0.80(0.40$ to 1.61$)$ \\
\hline $\begin{array}{l}\text { INTERGROWTH }<25 \text { th } \\
\text { centile }\end{array}$ & $7 / 225(3.1 \%)$ & 0.56 (0.09 to 3.46$)$ & $\begin{array}{l}1.58(0.81 \text { to } \\
3.07)\end{array}$ & $2.15(1.09 \text { to } 4.23)^{*}$ & $\begin{array}{l}3.66(1.04 \text { to } \\
12.88)^{*}\end{array}$ & 1.21 (0.63 to 2.33$)$ \\
\hline WHO $<25$ th centile & $\begin{array}{l}37 / 225 \\
(16.4 \%)\end{array}$ & $1.22(0.70$ to 2.12$)$ & $\begin{array}{l}1.83(1.31 \text { to } \\
2.57)^{* * * *}\end{array}$ & $1.77(1.13 \text { to } 2.76)^{*}$ & $\begin{array}{l}2.96(1.25 \text { to } \\
7.02)^{*}\end{array}$ & 1.22 (0.70 to 2.12$)$ \\
\hline
\end{tabular}

\section{Discussion}

This study demonstrates that GROW and INTE RGROWTH growth standards perform comparably in type 1 diabetes pregnancies, giving similar median birthweight centiles and comparable rates of LGA and SGA neonates. Furthermore, both GROW and INTE RGROWTH defined LGA identified neonates at increased risk of complications. LGA defined according to GROW (>90th and/or $>97.7$ th centile) showed stronger associations with preterm delivery, neonatal hypoglycaemia, hyperbilirubinaemia and NICU admission. In smaller infants, SGA defined according to INTERGROWTH criteria showed slightly stronger associations with outcomes. However, using any thresholds studied, weight related measures alone were not strong predictors of suboptimal perinatal outcomes (Table 3).

WHO standards do not incorporate gestational age at delivery, and thus fail to adequately describe size at birth in preterm infants. For term infants, the WHO criteria gave a true birthweight centile, but for preterm infants, the WHO criteria gave a low centile, which reflected their prematurity, not their comparative size at birth. 


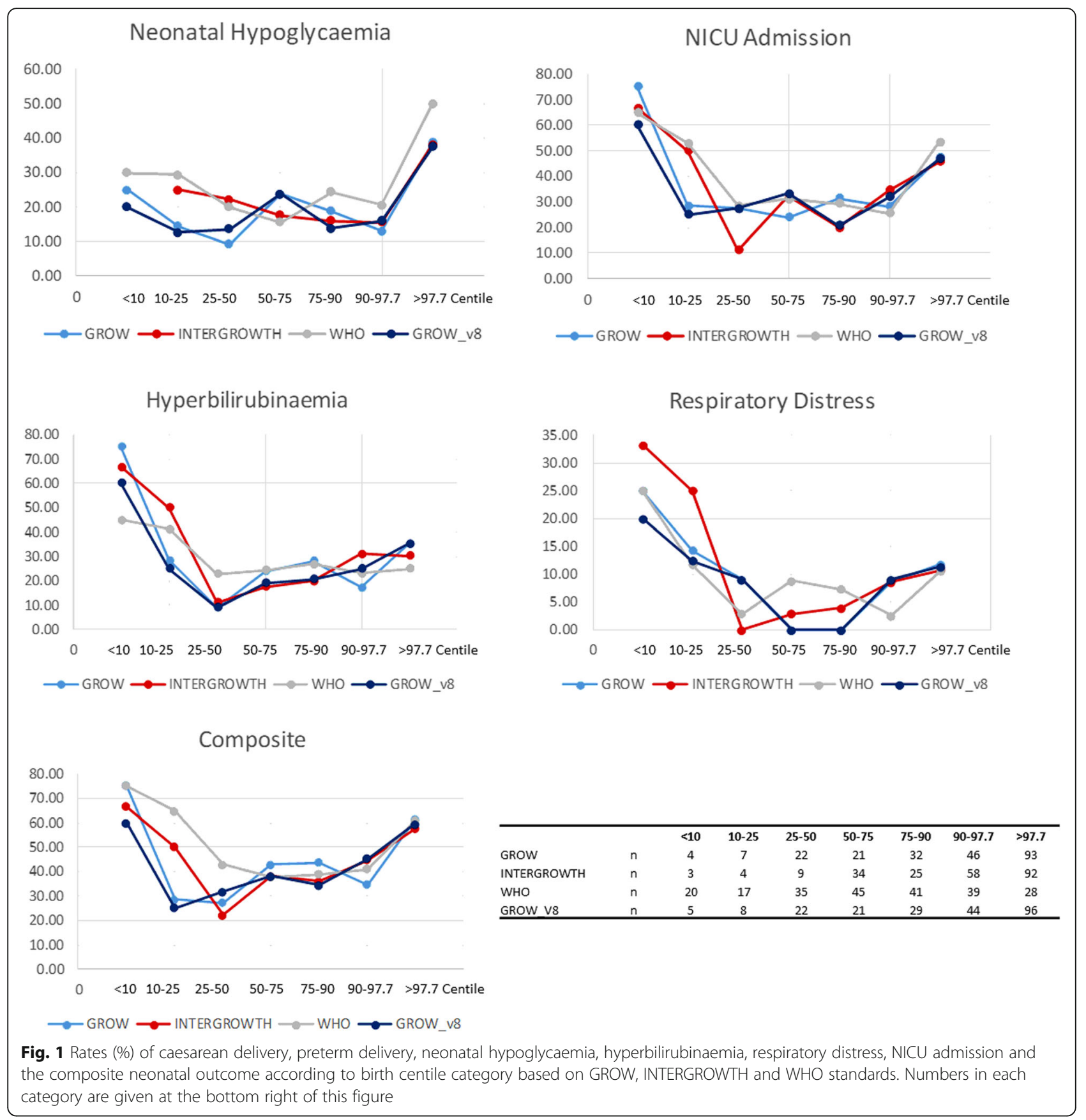

This measure of prematurity means that the WHO criteria were still able to predict outcomes, which demonstrates the importance of preterm delivery in relation to multiple neonatal complications. However, the inability to reliably attribute a birthweight centile is a substantial limitation in type 1 diabetes pregnancies, where rates of preterm delivery are as high as $40 \%$ [5].

A central aspect to the controversy about GROW and INTERGROWTH centiles involves the perceived importance of maternal factors to the growth of the infant, and ethnicity in particular. Proponents of GROW customised centiles believe that incorporating maternal variables results in a more accurate representation of size at birth $[9,19]$. Conversely, proponents of the INTE RGROWTH-21st standards claim that variables such as ethnicity make little difference to size at birth, in wellnourished populations with access to adequate antenatal care [13]. A limitation of the CONCEPTT trial is that while it international, $86 \%$ of women recruited were of European / Mediterranean origin, which reduced the opportunity to look at growth standard performance in different ethnicities. A further issue is that women who 


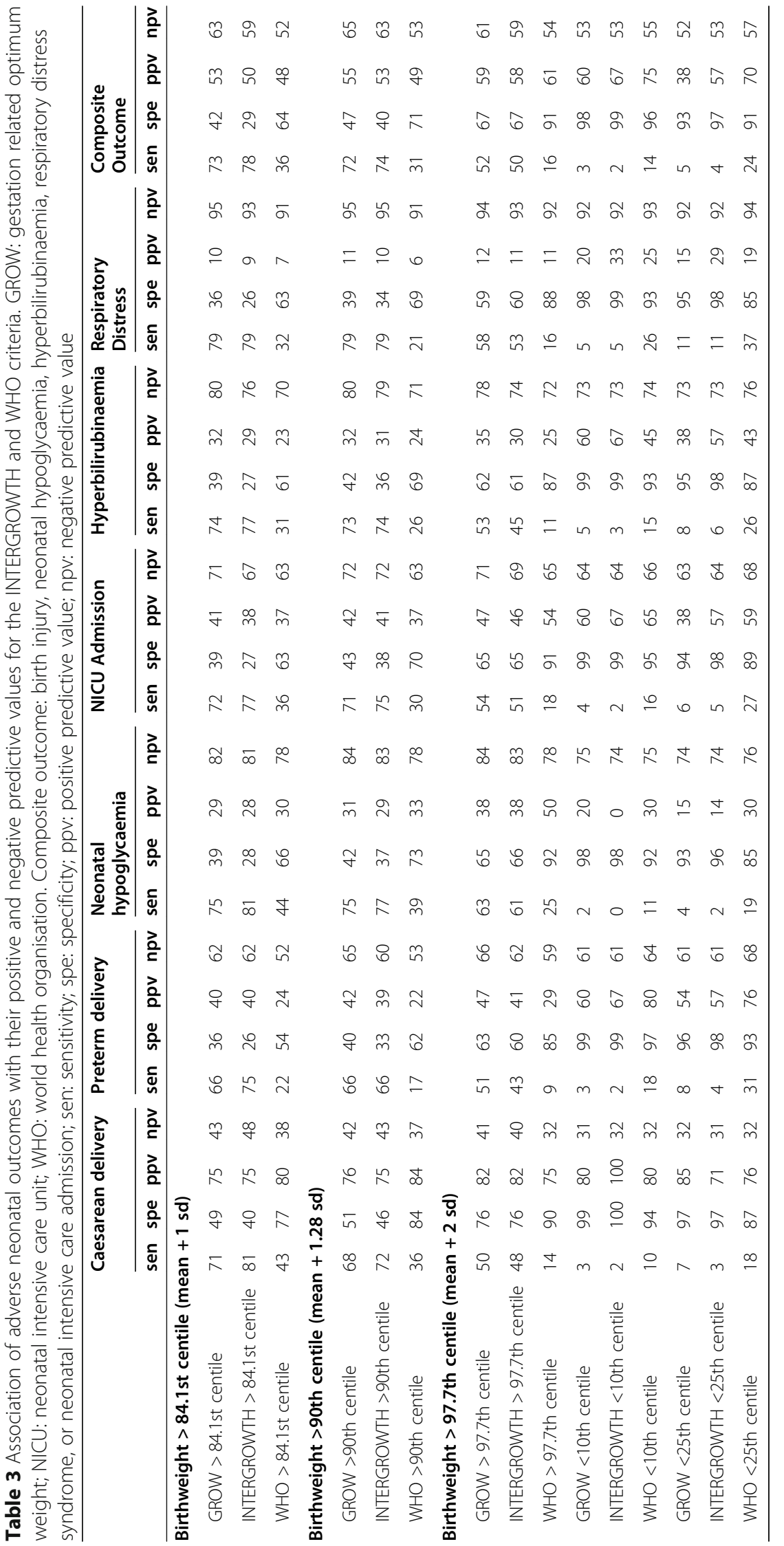


choose to participate in studies are often affluent, wellnourished and educated, and may not represent mothers with different socioeconomic circumstances.

A major focus for growth standards has been on the identification of infants who are SGA with a view to reducing stillbirth rates [9]. Although we have identified that infants $<25$ th centile displayed a trend to be at highest risk of multiple complications, very few infants fell into this category which made detailed assessment of SGA outcomes challenging. Although SGA is uncommon in type 1 diabetes pregnancy, it is plausible that infants born $<10$ th centile do not represent all those with growth restriction.

In this study, standard-deviation-based criteria for the diagnosis of LGA have been assessed. Although a birth weight $\mathrm{z}$ score $>1$ is considered consistent with LGA, this definition is different to standard centile-based definitions (>90th centile) [20]. Different approaches to the LGA diagnosis contribute to difficulty in comparing populations internationally [21-23].

A fundamental aim of antenatal care in T1D pregnancies involves careful control of maternal glycaemia to normalise fetal growth. This study shows that growth related measures alone are not strong predictors of suboptimal perinatal outcomes. For example, a birthweight $>$ 90th centile on GROW and INTERGROWTH criteria could identify neonatal hypoglycaemia, NICU admission and respiratory distress with $71-77 \%$ sensitivity, but the specificity for these outcomes was around $32-42 \%$.

These data are consistent with other work which highlights the challenges of accurate prediction of neonatal outcomes in T1D pregnancy. For example, Yamamoto and colleagues demonstrated that LGA was the only significant predictor for neonatal hypoglycaemia on adjusted logistic regression analysis (odds ratio 2.51, 95\% CI 1.10-5.70) [24]. However, $36 \%$ of infants with neonatal hypoglycaemia were appropriate for gestational age, resulting in similar levels of sensitivity and specificity seen in the current report.

As only a small proportion of the general maternity population has type 1 diabetes, CONCEPTT represents one of the larger randomised trials with detailed data on perinatal outcomes, making it useful to assess fetal growth, and infant birthweight outcomes. Customised (GROW) centiles were reported for CONCEPTT, but the effect of the intervention was also seen using INTE RGROWTH standards. Although accelerated fetal growth is common in T1D pregnancies, the rates of LGA in the CONCEPTT infants were higher than expected (66\% in CONCEPTT compared to $\sim 50 \%$ in a UK population using similar methodology [5]). The reasons for this are unclear, particularly as the CONCEPTT population had better glycaemic control compared to the UK clinical population [5].
Despite maternal diabetes being a risk factor of perinatal morbidity, there has been relatively little assessment of different growth standards in this population. Kase and colleagues reported that customised centiles identified more infants as SGA/LGA compared to population centiles in diabetes pregnancies [25]. Narchi and Skinner had similar findings but concluded there was no evidence of a difference in mortality or morbidity between the infants identified by customised vs population growth standards [26]. The current study adds to the literature by highlighting differences between the common growth standards in a generalisable population of pregnant women with type 1 diabetes. We had no women with optimal glucose control (defined as HbA1c $<48$ $\mathrm{mmol} / \mathrm{mol}$ ) in early pregnancy as these women were excluded from the CONCEPTT trial. However, population based studies confirm that only $15 \%$ of women with T1D achieve a first trimester HbA1c level $<6.5 \%(48$ $\mathrm{mmol} / \mathrm{mol}[5])$ and thus the data presented here is representative for the vast majority of women. Future studies should evaluate growth standards and definitions of LGA and SGA in larger cohorts of women with diabetes, including among women with target $\mathrm{HbA1c}$ levels. Better understanding of the causes and early identification of growth restriction in diabetes pregnancy should be a research priority.

\section{Conclusions}

WHO growth standards do not incorporate gestational age at birth and therefore are unsuitable for use in type 1 diabetes pregnancy, where preterm delivery is commonplace. However, GROW and INTERGROWTH standards are both suitable. Infants born $>97.7$ th centile had the highest risks of suboptimal outcomes. LGA defined by GROW and SGA defined by INTERGROWTH showed strongest associations with neonatal outcomes.

\section{Abbreviations \\ LGA: Large for gestational age; SGA: Small for gestational age; \\ CONCEPTT: Continuous Glucose Monitoring in Type 1 Diabetes Pregnancy Trial; NICU: Neonatal intensive care unit; T1D: Type 1 diabetes; \\ CGM: Continuous glucose monitoring; GROW: Gestation Related Optimum Weight; WHO: World Health Organisation; SD: Standard deviation; BMI: Body mass index}

\section{Acknowledgements}

The authors would like to thank all the women with type 1 diabetes who participated in the CONCEPTT trial. We also acknowledge the invaluable support from the 31 clinical care teams and the CONCEPTT Steering Committee: Denice S Feig, Helen R Murphy, Elisabeth Asztalos, Jon F R Barrett, Rosa Corcoy, Alberto de Leiva, Lois E Donovan, J Moshe Hod, Lois Jovanovic, Erin Keely, Craig Kollman, Ruth McManus, Kellie E Murphy, Katrina Ruedy and George Tomlinson.

\section{Authors' contributions}

CLM designed the study, analysed and interpreted the data, wrote and revised the manuscript. HRM identified the study question, contributed to data analysis, reviewed and revised the manuscript and contributed to the discussion. DSF, EL and RC contributed to study design, data collection, data collation and reviewed and revised the final manuscript. EA and LCK 
contributed to the discussion and reviewed the final manuscript. All authors gave approval of the final version of the manuscript prior to publication.

\section{Funding}

The trial is funded by Juvenile Diabetes Research Foundation (JDRF) grants \#17-2011-533, and grants under the JDRF Canadian Clinical Trial Network, a public-private partnership including JDRF and FedDev Ontario and supported by JDRF \#80-2010-585. The funders provided solely the finance required for this study and had no role in the trial design, data collection, data analysis or data interpretation. Medtronic supplied the CGM sensors and CGM systems at reduced cost. They also had no role in trial design, collection, handling, analysis or interpretation of data.

HRM conducts independent research supported by the National Institute for Health Research (Career Development Fellowship, CDF-2013-06-035), and is supported by Tommy's charity. CLM is supported by the Diabetes UK Harry Keen Intermediate Clinical Fellowship (DUK-HKF 17/0005712) and the EFSDNovo Nordisk Foundation Future Leader's Award (NNF19SA058974).

\section{Availability of data and materials}

The datasets used and/or analysed during the current study are available from the corresponding author on reasonable request.

\section{Ethics approval and consent to participate}

The CONCEPTT study was approved by the Research Ethics Committee East of England (Essex) under reference 12/EE/0310 in 2012. All participants provided written informed consent. Further ethical approval was not required for this analysis.

\section{Consent for publication}

Not applicable.

\section{Competing interests}

Denice Feig has received honoraria for speaking engagements from Medtronic and has been on an.

Helen Murphy has received honoraria for speaking engagements from Medtronic, Roche, Novo Nordisk, Eli-Lilly and is a member of the Medtronic European Advisory Board.

CLM is the guarantor of this work and, as such, has had full access to all the data in the study and takes responsibility for the integrity of the data and the accuracy of the data analysis.

\section{Author details}

${ }^{1}$ Institute of Metabolic Science, University of Cambridge, Addenbrooke's Hospital, Box 289, Cambridge CB2 0QQ, UK. ${ }^{2}$ Cambridge Universities NHS Foundation Trust, Cambridge, UK. 35ervei d'Endocrinologia i Nutrició, Hospital de la Santa Creu i Sant Pau, Barcelona, Spain. ${ }^{4}$ Institut de Recerca, Hospital de la Santa Creu i Sant Pau, CIBER-BBN, Barcelona, Spain. ${ }^{5}$ Department de Medicina, Universitat Autònoma de Barcelona, Barcelona, Spain. ${ }^{6}$ Sunnybrook Health Sciences Centre, University of Toronto, Toronto, Canada. ${ }^{7}$ Servei de Pediatria, Hospital de la Santa Creu i Sant Pau, Barcelona, Spain. ${ }^{8}$ Mount Sinai Hospital, Department of Medicine, University of Toronto, Toronto, Canada. ${ }^{9}$ Lunenfeld-Tanenbaum Research Institute, Toronto, Canada. ${ }^{10}$ Norwich Medical School, University of East Anglia, Norwich, UK. ${ }^{11}$ Department of Women and Children's Health, King's College London, London, UK.

Received: 13 May 2020 Accepted: 12 January 2021

Published online: 29 January 2021

\section{Supplementary Information}

The online version contains supplementary material available at https://doi. org/10.1186/s12884-021-03554-6.

\section{Additional file 1}

\section{Author details}

The online version contains supplementary material available at https://doi. org/10.1186/s12884-021-03554-6.

${ }^{1}$ Institute of Metabolic Science, University of Cambridge, Addenbrooke's Hospital, Box 289, Cambridge CB2 0QQ, UK. ${ }^{2}$ Cambridge Universities NHS
Foundation Trust, Cambridge, UK. ${ }^{3}$ Servei d'Endocrinologia i Nutrició, Hospital de la Santa Creu i Sant Pau, Barcelona, Spain. ${ }^{4}$ Institut de Recerca, Hospital de la Santa Creu i Sant Pau, CIBER-BBN, Barcelona, Spain. ${ }^{5}$ Department de Medicina, Universitat Autònoma de Barcelona, Barcelona, Spain. ${ }^{6}$ Sunnybrook Health Sciences Centre, University of Toronto, Toronto, Canada. ${ }^{7}$ Servei de Pediatria, Hospital de la Santa Creu i Sant Pau, Barcelona, Spain. ${ }^{8}$ Mount Sinai Hospital, Department of Medicine, University of Toronto, Toronto, Canada. ${ }^{9}$ Lunenfeld-Tanenbaum Research Institute, Toronto, Canada. ${ }^{10}$ Norwich Medical School, University of East Anglia, Norwich, UK. ${ }^{11}$ Department of Women and Children's Health, King's College London, London, UK.

Received: 13 May 2020 Accepted: 12 January 2021

Published online: 29 January 2021

\section{References}

1. Weaver LT. In the balance: weighing babies and the birth of the infant welfare clinic. Bull Hist Med. 2010;84(1):30-57 [published Online First: 2010/ 07/17].

2. Clarke JD. Observations on some causes of excess mortality of males above that of females. Philos Trans R Soc Lond. 1786;76:349-64.

3. Ray JG, Park AL, Fell DB. Mortality in Infants Affected by Preterm Birth and Severe Small-for-Gestational Age Birth Weight. Pediatrics. 2017:140(6). https://doi.org/10.1542/peds.2017-1881 [published Online First: 2017/11/10].

4. Doty MS, Chen HY, Sibai BM, et al. Maternal and Neonatal Morbidity Associated With Early Term Delivery of Large-for-Gestational-Age But Nonmacrosomic Neonates. Obstet Gynecol. 2019;133(6):1160-6. https://doi. org/10.1097/aog.0000000000003285 [published Online First: 2019/05/29].

5. Murphy HR, Bell R, Cartwright C, et al. Improved pregnancy outcomes in women with type 1 and type 2 diabetes but substantial clinic-to-clinic variations: a prospective nationwide study. Diabetologia. 2017;60(9):1668-77. https://doi.org/10.1007/s00125-017-4314-3 [published Online First: 2017/06/ 10]

6. Feig DS, Donovan LE, Corcoy R, et al. Continuous glucose monitoring in pregnant women with type 1 diabetes (CONCEPTT): a multicentre international randomised controlled trial. Lancet. 2017:390(10110):2347-59. https://doi.org/10.1016/S0140-6736(17)32400-5 [published Online First: 2017/09/15]

7. Murphy HR. Continuous glucose monitoring targets in type 1 diabetes pregnancy: every 5\% time in range matters. Diabetologia. 2019;62(7):1123-8. https://doi.org/10.1007/s00125-019-4904-3 [published Online First: 2019/06/ 05]

8. Gardosi JFA. Gestation network. Customised weight centile calculator. GROW v8.1 UK. http://www.gestation.net/birthweight_centiles/centile_ object.htm

9. Francis A, Hugh O, Gardosi J. Customized vs INTERGROWTH-21(st) standards for the assessment of birthweight and stillbirth risk at term. Am J Obstet Gynecol. 2018;218(2s):S692-s99. https://doi.org/10.1016/j.ajog.2017.12.013 [published Online First: 2018/02/10].

10. Gardosi J, Clausson B, Francis A. The value of customised centiles in assessing perinatal mortality risk associated with parity and maternal size. Bjog. 2009;116(10):1356-63. https://doi.org/10.1111/j.1471-0528.2009.02245.x [published Online First: 2009/06/23].

11. Villar J, Cheikh Ismail L, Victora CG, et al. International standards for newborn weight, length, and head circumference by gestational age and sex: the Newborn Cross-Sectional Study of the INTERGROWTH-21st Project. Lancet. 2014;384(9946):857-68. https://doi.org/10.1016/s0140-6736(14)609326 [published Online First: 2014/09/12].

12. WHO Multicentre Growth Reference Study Group. WHO Child Growth Standards based on length/height, weight and age. Acta Paediatr Suppl. 2006:450:76-85 [published Online First: 2006/07/05]. https://www.who.int/ childgrowth/standards/Acta_95_S450.pdf?ua=1.

13. Papageorghiou AT, Kennedy SH, Salomon LJ, et al. The INTERGROWTH-21(st) fetal growth standards: toward the global integration of pregnancy and pediatric care. Am J Obstet Gynecol. 2018;218(2s):S630-s40. https://doi.org/ 10.1016/j.ajog.2018.01.011 [published Online First: 2018/02/10].

14. Anderson NH, Sadler LC, Stewart AW, et al. Maternal and pathological pregnancy characteristics in customised birthweight centiles and identification of at-risk small-for-gestational-age infants: a retrospective cohort study. BJOG. 2012;119(7):848-56. https://doi.org/10.1111/j.1471-0528. 2012.03313.x [published Online First: 2012/04/04]. 
15. Mackin ST, Nelson SM, Kerssens JJ, et al. Diabetes and pregnancy: national trends over a 15 year period. Diabetologia. 2018;61(5):1081-8. https://doi. org/10.1007/s00125-017-4529-3.

16. Hadlock FP, Harrist RB, Martinez-Poyer J. In utero analysis of fetal growth: a sonographic weight standard. Radiology. 1991;181(1):129-33. https://doi. org/10.1148/radiology.181.1.1887021.

17. Villar J, Giuliani F, Fenton TR, Ohuma EO, Ismail LC, Kennedy SH; INTERGROWTH-21st Consortium. INTERGROWTH-21st very preterm size at birth reference charts. Lancet. 2016;387(10021):844-5.

18. Stefanelli S, Groom KM. The accuracy of ultrasound-estimated fetal weight in extremely preterm infants: a comparison of small for gestational age and appropriate for gestational age. Aust N Z J Obstet Gynaecol. 2014;54(2):12631. https://doi.org/10.1111/ajo.12198 [published Online First: 2014/02/28].

19. Anderson NH, Sadler LC, McKinlay CJD, et al. INTERGROWTH-21st vs customized birthweight standards for identification of perinatal mortality and morbidity. Am J Obstet Gynecol. 2016;214(4):509.e1-7. https://doi.org/ 10.1016/j.ajog.2015.10.931 [published Online First: 2015/11/08].

20. Blickstein I, Salihu HM, Keith LG, et al. The association between small-forgestational age triplet pregnancies and neonatal mortality: a novel approach to growth assessment in multiple gestations. Pediatr Res. 2006; 59(4 Pt 1):565-9. https://doi.org/10.1203/01.pdr.0000202757.47761.76 [published Online First: 2006/03/22]

21. Persson M, Norman M, Hanson U. Obstetric and perinatal outcomes in type 1 diabetic pregnancies: A large, population-based study. Diabetes Care. 2009;32(11):2005-9. https://doi.org/10.2337/dc09-0656 [published Online First: 2009/08/14]

22. Persson M, Pasupathy D, Hanson U, et al. Birth size distribution in 3,705 infants born to mothers with type 1 diabetes: a population-based study. Diabetes Care. 2011;34(5):1145-9. https://doi.org/10.2337/dc10-2406 [published Online First: 2011/03/25].

23. Murphy HR, Rayman G, Lewis K, et al. Effectiveness of continuous glucose monitoring in pregnant women with diabetes: randomised clinical trial. BMJ. 2008;337:a1680 [published Online First: 2008/09/25].

24. Yamamoto JM, Kallas-Koeman MM, Butalia S, et al. Large-for-gestational-age (LGA) neonate predicts a 2.5 -fold increased odds of neonatal hypoglycaemia in women with type 1 diabetes. Diabetes Metab Res Rev. 2017;33(1). https:// doi.org/10.1002/dmrr.2824 [published Online First: 2016/05/18].

25. Kase BA, Cormier CM, Costantine MM, et al. Population standards of birth weight underestimate fetal growth abnormalities in diabetic pregnancies. Am J Perinatol. 2012;29(2):147-52. https://doi.org/10.1055/s-0031-1295656 [published Online First: 2011/11/23].

26. Narchi H, Skinner A. Infants of diabetic mothers with abnormal fetal growth missed by standard growth charts. J Obstet Gynaecol. 2009;29(7):609-13. https:/ doi.org/10.1080/01443610903100625 [published Online First: 2009/09/17].

\section{Publisher's Note}

Springer Nature remains neutral with regard to jurisdictional claims in published maps and institutional affiliations.

Ready to submit your research? Choose BMC and benefit from:

- fast, convenient online submission

- thorough peer review by experienced researchers in your field

- rapid publication on acceptance

- support for research data, including large and complex data types

- gold Open Access which fosters wider collaboration and increased citations

- maximum visibility for your research: over $100 \mathrm{M}$ website views per year

At $\mathrm{BMC}$, research is always in progress.

Learn more biomedcentral.com/submissions 